\title{
Keuzehulp voor cystectomiepatiënten: stomaofneoblaas.nl
}

\author{
Julia J. van Tol-Geerdink' • D. M. (Rik) Somford ${ }^{2}$ Carl J. Wijburg ${ }^{3}$ A. G. (Toine) van der Heijden ${ }^{4}$ \\ J. A. (Fred) Witjes ${ }^{4}$
}

Published online: 7 November 2018

(c) The Author(s) 2018

\section{Samenvatting}

In geval van radicale cystectomie staan veel patiënten voor de keuze tussen een stoma of een neoblaas voor urinederivatie. Als ondersteuning in deze beslissing is een keuzehulp ontwikkeld met de voor- en nadelen van beide opties. De keuzehulp werd ontwikkeld met patiënten en zorgverleners. Evaluatie gebeurde middels vragenlijsten in een bruikbaarheidstudie. Hiertoe werden vragenlijsten ingevuld door 37 patiënten: 25 met en 12 zonder keuzehulp. De keuzehulp werd positief geëvalueerd. Met keuzehulp werden meer kennisvragen correct beantwoord $(96 \%$ vs. $83 \%$; $p=0,066)$ en waren meer patiënten actief betrokken in de keuze $(100 \%$ vs. $75 \% ; p=0,011)$. Patiënten ontvingen de keuzehulp op de dag van het diagnosegesprek (38\%), één tot zeven dagen erna (19\%) of later (43\%). Tevredenheid met de timing verschilde tussen die momenten (resp. 88\%, $100 \%$ en $33 \%$ tevreden, $p=0,018$ ). De keuzehulp werd positief beoordeeld en deed alle patiënten actief meebeslissen. De keuzehulp kan direct na de diagnose worden uitgereikt.

Trefwoorden radicale cystectomie $\cdot \operatorname{keuzehulp} \cdot$ stoma $\cdot$ neoblaas

\section{Decision aid for cystectomy patients: stoma or neobladder}

\begin{abstract}
In case of radical cystectomy, many patients face a choice between a stoma or a neobladder for urine derivation. To facilitate this decision, we developed a decision aid (DA). Urologists, specialized nurses and patients were involved in developing the DA. New patients evaluated the DA by questionnaire. The DA was evaluated positively on content and usability. In total, 37 patients filled out questionnaires; 25 with and 12 without DA. The DA improved knowledge (96\% vs. $83 \%, p=0.066)$ and active participation in decision making $(100 \% v s .75 \%, p=0.011)$. Patients received the DA on the day of diagnosis $(38 \%)$, one to seven days after diagnosis $(19 \%)$ or later $(43 \%)$. Satisfaction with the timing differed between these groups (resp. 88\%, 100\% and 33\% satisfied, $p=0.018$ ). The DA was evaluated positively and made all patients participate actively in decision making. The decision aid can be offered shortly after diagnosis.
\end{abstract}

Keywords radical cystectomy $\cdot$ decision aid $\cdot$ stoma $\cdot$ neobladder

dr. Julia J. van Tol-Geerdink

julia.vantol-geerdink@radboudumc.nl

afdeling Radiotherapie, Radboudumc, Nijmegen, Nederland

2 afdeling Urologie, Canisius Wilhelmina Ziekenhuis, Nijmegen, Nederland

3 afdeling Urologie, Rijnstate Ziekenhuis, Arnhem, Nederland

4 afdeling Urologie, Radboudumc, Nijmegen, Nederland

\section{Introductie}

$\mathrm{Na}$ een blaasverwijdering (radicale cystectomie) bestaan er verschillende oplossingen voor de afvoer van urine. Er kan een nieuwe blaas uit darmweefsel (neoblaas) worden aangelegd, een stoma waarbij de urine wordt opgevangen in een zakje aan de buitenzijde van het lichaam (nat stoma) of in een inwendig reservoir (droog stoma), en er kan een aansluiting worden gemaakt op de endeldarm, waarbij de urine via de anus het lichaam verlaat. De twee meest toegepaste behandelingen zijn het natte stoma volgens de methode Bricker en de orthotope neoblaas [1]. Deze opties 
zijn medisch gezien gelijkwaardig, maar elk heeft voor- en nadelen. Op grond van studies is geen 'beste' behandeling aan te wijzen. Er zijn geen gerandomiseerde studies beschikbaar die zich richten op de vergelijking tussen de verschillende opties van urineafvoer. In reviews van nietgerandomiseerde onderzoeken wordt geen significant verschil aangetoond in morbiditeit, zoals infectie, stenose, verslechterde nierfunctie, of in algemene kwaliteit van leven [2-6]. Hierbij moet worden aangemerkt dat de reviews met name concludeerden dat er tot op heden onvoldoende aanwijzing is om één behandeling als superieur te bestempelen. Een review van Ali et al. beschrijft 21 studies, waarvan er 16 geen verschil vonden, 4 een betere kwaliteit van leven met neoblaas aantoonden, en 1 een betere kwaliteit van leven met stoma [7]. Hun voorzichtige conclusie is dat een neoblaas een marginaal betere kwaliteit van leven oplevert, met name voor jongere en fittere patiënten. Buiten de review, beschrijven ook Singh et al. betere uitkomsten met de neoblaas [8].

Belangrijk is echter de aanbeveling van Evans et al. dat de focus niet gericht moet zijn op het bepalen van welke behandeling superieur is, maar op welke behandeling het best past bij de individuele patiënt [3]. Een neoblaas kan voordelen hebben zoals een beter lichamelijk zelfbeeld [9, 10], beter seksueel functioneren [11], maar ook nadelen, zoals een langere operatietijd [12], kans op metabole acidose [6], op blijvende nachtelijke incontinentie [9, 11, 13] en (zelf)katheterisatie [9, 14]. Verder vraagt de neoblaas vooral meer toewijding en zelfdiscipline van de patiënt voor de blaastraining om de nieuwe manier van plassen aan te leren [11]. De besluitvorming rond deze keuze vraagt dan ook om informatie, participatie en discussie, zodat de patiëntvoorkeur een belangrijke rol in de behandelkeuze kan spelen [3, 15]. De keuze tussen een stoma of neoblaas wordt nu vaak bepaald door kenmerken van ziekenhuis en patiënten. Er wordt vaker tot een stoma besloten wanneer het ziekenhuis relatief weinig cystectomieën uitvoert, bij patiënten met een hogere leeftijd, bij patiënten met meer comorbiditeit en bij vrouwen [16, 17]. In deze beslissing zou echter de voorkeur van de patiënt sterk moeten worden meegewogen [2-4, 18]. De huidige richtlijn geeft immers aan: "Patiënten moeten geïnformeerd worden over de verschillende opties en de uiteindelijke keuze moet tot stand komen in samenspraak met de patiënt" [19]. Een keuzehulp is daarvoor het geëigende hulpmiddel, en wordt voor deze keuze dan ook bepleit [15]. Een keuzehulp geeft informatie over voor- en nadelen van verschillende opties en stimuleert patiënten om te bedenken welke voor- en nadelen voor hen persoonlijk het zwaarst wegen. Keuzehulpen zijn effectief gebleken in het verhogen van kennis en het verlagen van twijfel [20-24].
Dit artikel beschrijft de ontwikkeling van een dergelijke keuzehulp en de bruikbaarheidstudie die daarmee is uitgevoerd.

\section{Methode}

De keuzehulp is ontwikkeld conform de International Patient Decision Aid Standards (IPDAS) [25]. Daarbij is het ontwikkelingsmodel van Coulter et al. gebruikt [26].

Er zijn drie verschillende focusgroepen opgezet: een van patiënten (van de vereniging Leven met Blaas- of Nierkanker), een van urologen en een van oncologieverpleegkundigen met ervaring met perioperatieve zorg of nazorg voor cystectomiepatiënten. Daarin is gevraagd om aan te geven welke informatie zij noodzakelijk achtten om de keuze tussen een stoma en een neoblaas te kunnen maken. Op grond van de verkregen informatie is een prototype van de keuzehulp ontwikkeld.

Er is bewust gekozen voor een keuzehulp in digitale vorm, om (terugkerende) drukkosten, problemen met verspreiding en updates in de toekomst te voorkomen. Voor de opbouw van de keuzehulp werd een indeling gebruikt op basis van het model van het Ottawa Hospital Research Center [27].

Het prototype is vervolgens voor feedback over de vorm en de inhoud voorgelegd aan de eindgebruikers: patiënten en zorgverleners ( $\alpha$-testing).

\section{Bruikbaarheidstudie}

De keuzehulp is opgenomen in het lokale zorgpad voor blaaskanker in overleg met de zorgverleners in de drie deelnemende ziekenhuizen: het Radboudumc en het Canisius Wilhelmina Ziekenhuis, beide in Nijmegen en het Rijnstate Ziekenhuis in Arnhem. De keuzehulp werd aanboden door de uroloog, de oncologieverpleegkundige of de stomaverpleegkundige. Dit gebeurde in de vorm van een kaart (keuzehulp op recept) waarop een korte toelichting op de keuzehulp stond, evenals het webadres en een inlogcode. De patiënten konden vervolgens met behulp van de inlogcode vanuit huis de keuzehulp doornemen, eventueel samen met hun partner. Indien gewenst konden patiënten een afdruk maken van hun afwegingen om deze mee te nemen naar het consult met de uroloog. In een afrondend consult met de uroloog werden de afwegingen met de patiënt besproken en werd een keuze gemaakt.

In deze studie werden de patiënten niet gerandomiseerd naar een interventiearm (met keuzehulp) of een controlearm (zonder keuzehulp), omdat niet valt uit te sluiten dat de zorgverleners in hun consultvoering beïnvloed werden door de invoering van de keuzehulp. Om die reden 
is gekozen voor een cohortdesign. De controlegroep werd geïncludeerd vóór ingebruikname van de keuzehulp (februari-juni 2016) en de interventiegroep erna (juli 2016-december 2017).

$\mathrm{Na}$ de beslissing over de urinederivatie, maar vóór de operatie, ontvingen de patiënten een vragenlijst over demografische kenmerken, de keuze, de rol van de patiënt in de besluitvorming, decisional conflict [28] en kennis (aan de hand van 5 stellingen). Bij patiënten die de keuzehulp hadden ontvangen, werden extra vragen toegevoegd over de inhoud van de keuzehulp en het moment van aanbieden daarvan.

De studie is door de CMO als niet WMO-plichtig beoordeeld (dossier 2016-2381).

\section{Resultaten}

De volgende zes stappen vormen de basisstructuur van de digitale keuzehulp: (1) Introductie (om aan te geven dat er een keuze is), (2) Welke opties staan open?, (3) Vooren nadelen van de opties, (4) Test uw kennis (om te testen of de informatie begrepen is), (4) Welke voor- en nadelen wegen voor $\mathrm{u}$ het zwaarst? (om een persoonlijke afweging te maken) en (5) Resultaat.

Elke stap is onderverdeeld in kleine hoofdstukken. Patiënten worden uitgenodigd om alle stappen door te nemen. Zij kunnen daarbij ook terugbladeren naar voorgaande stappen en hoofdstukjes.

In stap $1 \mathrm{t} / \mathrm{m} 3 \mathrm{krijgt}$ de patiënt informatie over de opties voor urineafvoer, namelijk stoma of neoblaas (vervangblaas). De kenmerken van beide opties worden beschreven met eenvoudige illustraties. De presentatie van de vooren nadelen is neutraal gesteld. De kansen op bijwerkingen worden steeds uitgedrukt in aantal per 100 patiënten.

\section{Keuzehulp stoma of vervangblaas}

stap 1

introductie stap 2

behandelingen stap 3

voor \& nadelen stap 4

kennistest stap 5

afwegingen stap 6

resultaat

\section{Afweging van voor- en nadelen}

Hieronder kunt u aangeven hoe belangrijk de verschillende uitkomsten voor u zijn.

Door het schuifje weinig of veel te verplaatsen in de richting van een van de uitspraken, kunt $u$ aangeven dat $u$ het met die uitspraak een beetje of helemaal eens bent.

\section{Uiterlijk}

Uiterlijk van mijn lichaam met een stoma

is voor mij totaal geen probleem

Uiterlijk van mijn lichaam met een stoma is voor mij een erg groot probleem

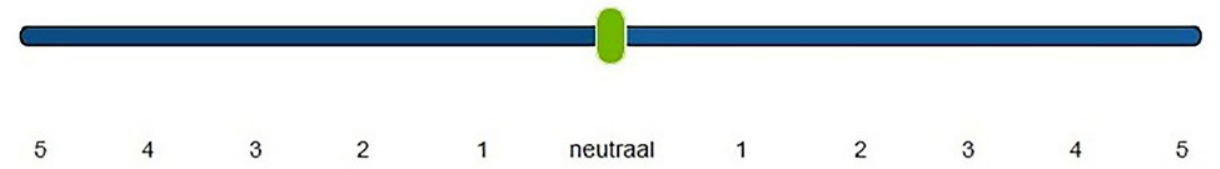

\section{Gemak}

Ik zie erg op tegen het aanleren van nieuw plasgedrag en zie meer in net gemak van een stoma

Het aanleren van nieuw plasgedrag is voor mij geen enkel probleem

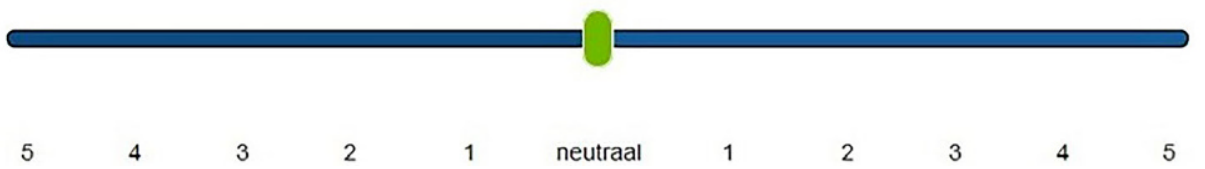

Figuur 1 Screenshot van (deel van) de afwegingen in stap 5 van de keuzehulp 
Stap 4 bestaat uit kennisvragen. Na beantwoording is direct zichtbaar of het antwoord correct is, en is het correcte antwoord te zien.

In stap 5 krijgt de patiënt zes uitspraken ter overweging voorgelegd (fig. 1). De stellingen passen bij ofwel het stoma ofwel de neoblaas. Hierbij kunnen patiënten middels een schuifje aangeven in hoeverre zij het eens zijn met een bepaalde stelling. Onderaan de pagina staat: 'Hoe meer $\mathrm{u}$ het schuifje naar links heeft verplaatst, hoe beter een stoma bij uw voorkeur zou passen', en 'Hoe meer u het schuifje naar rechts heeft verplaatst, hoe beter een neoblaas bij uw voorkeur zou passen'.

In stap 6 krijgt de patiënt de mogelijkheid om de persoonlijke afwegingen te printen. Ook de eventuele vragen of opmerkingen die patiënten tijdens het lezen op het digitale kladblok hebben genoteerd, worden bij het resultaatblad afgedrukt. Deze afdruk kunnen patiënten desgewenst meenemen naar het overleg met de uroloog.

\section{Feedback van patiënten}

Het prototype van de keuzehulp is ter evaluatie eerst voorgelegd aan zeven ex-patiënten uit de deelnemende ziekenhuizen. De meeste feedback was positief. Quotes uit de ontvangen reacties luiden:

- "Ik heb de keuzehulp aandachtig doorgelezen. Het heeft een meerwaarde voor een ingrijpende beslissing die men moet nemen."

- "Mijn complimenten voor de keuzehulp. Ik ben er naar mijn idee nauwkeurig door heen gegaan en ik denk dat alle aspecten wel belicht zijn."

- "Ik zou willen dat ik zo'n keuzehulp had gekregen bij mijn voorbereiding op de operatie."

- "Ik denk dat toekomstige twijfelaars er veel aan hebben."

Daarnaast waren er ook kritiekpunten, zoals spelfouten, en het uitprinten van het resultaatblad bleek soms problematisch. Een tip was om de mogelijkheid van lotgenotencontact te benoemen in de keuzehulp. Deze aandachtspunten zijn in de keuzehulp verwerkt.

\section{Feedback van urologen}

De keuzehulp werd ook bekeken en beoordeeld door zes urologen uit drie ziekenhuizen. Zij deden vooral suggesties voor toevoegingen aan de medische inhoud. Door de reacties (via e-mail) te delen met alle betrokken urologen, kon er consensus worden bereikt over de formuleringen.

\section{Feedback van gespecialiseerde verpleegkundigen}

De keuzehulp werd tevens beoordeeld door zes verpleegkundigen die zijn gespecialiseerd in het werken met patiënten met blaaskanker. Deze verpleegkundigen verzorgen de informatievoorziening voorafgaand aan de operatie of zijn nauw betrokken bij de nazorg. Hun commentaar richtte zich met name op de leesbaarheid en de begrijpelijkheid van de informatie in de keuzehulp. Op hun aanraden is een aantal zinnen opgeknipt en zijn moeilijke woorden toegelicht of vervangen.

\section{Aanpassing van de keuzehulp}

Op grond van de ontvangen feedback is de tekst van de keuzehulp vervolgens aangepast. Daarnaast zijn aanwijzingen van de 'Stichting Makkelijk Lezen' opgevolgd: zij wijzen onder andere op het belang van een duidelijke opbouw, korte zinnen, eenvoudige woorden, voldoende wit rond de tekst, gebruik van illustraties, een groot lettertype en een ruime regelafstand.

\section{Bruikbaarheidstudie}

In totaal werd aan 47 patiënten gevraagd om aan de studie deel te nemen; van hen gaven 41 informed consent (87\%). Twee patiënten bleken na aanvullend onderzoek toch niet voor inclusie in aanmerking te komen vanwege metastasen $(n=1)$ of locatie van de tumor in de blaashals $(n=1)$. Twee andere patiënten stuurden geen vragenlijst retour. In totaal werden 37 vragenlijsten ontvangen; 12 van patiënten

Tabel 1 Patiëntkenmerken

\begin{tabular}{llll}
\hline Patiëntkenmerken & $\begin{array}{l}\text { zonder keuzehulp } \\
(n=12) \%\end{array}$ & $\begin{array}{l}\text { met keuzehulp } \\
(n=25) \%\end{array}$ & $p$ \\
\hline hoog opgeleid $(\geq \mathrm{hbo})$ & 27 & 29 & 0,91 \\
gehuwd/samenwonend & 75 & 84 & 0,41 \\
betaalde baan & 25 & 29 & 0,80 \\
leeftijd, gem & $66 \pm 7 \mathrm{jr}$ & $62 \pm 7 \mathrm{jr}$ & 0,15 \\
\hline
\end{tabular}

Tabel 2 Rol van patiënt in besluitvorming

\begin{tabular}{llcc}
\hline Wie bepaalde de keuze? & $\begin{array}{l}\text { zonder keuzehulp } \\
(n=12) \%\end{array}$ & $\begin{array}{l}\text { met keuzehulp } \\
(n=25) \%\end{array}$ & $p$ \\
\hline vooral/alleen de zorgverlener & 25 & 0 & 0,011 \\
samen of vooral/alleen de patiënt & 75 & 100 & \\
\hline
\end{tabular}


Tabel 3 Waar/niet-waar-stellingen

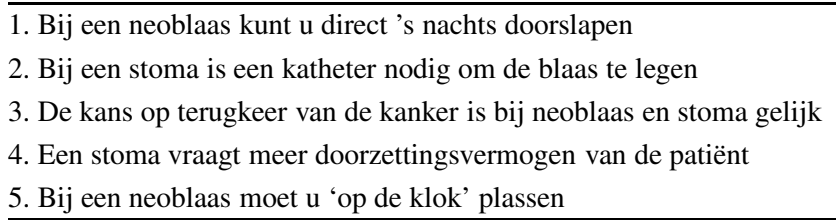

zonder keuzehulp (controlegroep) en 25 van patiënten met keuzehulp.

De patiëntkenmerken in de controlegroep (zonder keuzehulp) en de interventiegroep (met keuzehulp) waren vergelijkbaar (tab. 1).

De keuzehulp had geen significant effect op de keuze. In de keuzehulpgroep koos $54 \%$ voor een neoblaas tegenover $33 \%$ in de controlegroep $(p=0,25)$.

\section{Invloed op de besluitvorming}

Om de rol van de patiënt in de besluitvorming vast te stellen, werd de volgende vraag gesteld: 'Wie bepaalde welke oplossing (stoma of neoblaas) gekozen werd?' (tab. 2). In de controlegroep gaf $25 \%$ aan dat de keuze vooral of alleen door de zorgverlener (arts of verpleegkundige) werd bepaald, tegenover geen $(0 \%)$ van de patiënten in de keuzehulpgroep $(p=0,011)$. In de groep met keuzehulp gaven alle patiënten aan dat zij betrokken waren in de keuze.

\section{Invloed op het kennisniveau}

Kennis over neoblaas en stoma is gemeten aan de hand van vijf stellingen (tab. 3). Bij elke stelling kan de patiënt aangeven of deze 'waar' of 'niet waar' is. De keuzehulpgroep kreeg de stellingen voorgelegd in de keuzehulp. Hun eerste antwoord werd vastgelegd. Gewijzigde antwoorden, na feedback over de juistheid van hun antwoord, zijn genegeerd. De controlegroep kreeg de stellingen voorgelegd in de vragenlijst. Het percentage correcte antwoorden was bij patiënten zonder keuzehulp $83 \%$ en bij patiënten met keuzehulp 96\% ( $p=0,066)$. Het grootste verschil werd gevonden in de respons op stelling 3 . Terwijl alle patiënten in de interventiegroep (100\%) de stelling terecht als waar bestempelden, wist slechts $80 \%$ van de controlegroep dat de kans op terugkeer van de kanker niet afhankelijk is van de keuze tussen stoma en neoblaas $(p=0,02)$.

\section{Invloed op het decisonal conflict}

Decisional conflict is een belangrijke maat, die in veel besliskundige studies als primaire uitkomstmaat wordt gebruikt. De Decisional Conflict Scale (DCS) heeft meerdere subschalen [28]. De Values Clarity Scale geeft aan in hoeverre patiënten onzeker zijn of twijfelen over welke uitkomsten voor hen het belangrijkst zijn in de afweging tussen de behandelopties. Deze veel gebruikte conflictscore was $23,6 \pm 24$ in de controlegroep en $18,8 \pm 17$ in de interventiegroep $(p=0,49)$.

\section{Het delen van patiëntervaringen}

Alle patiënten met keuzehulp (100\%) zouden de manier waarop zij geïnformeerd werden aanraden aan anderen, vergeleken met $92 \%$ van de controlepatiënten.

\section{Studie naar de evaluatie en implementatie van de keuzehulp}

In totaal werden 25 mensen geïncludeerd die de keuzehulp kregen aangeboden voorafgaand aan de operatie waarbij de blaas werd verwijderd. Zij gebruikten de keuzehulp dus in de praktijk.

\section{Inhoud van de keuzehulp}

De inhoud van de keuzehulp werd positief beoordeeld. Alle patiënten $(100 \%)$ gaven aan dat zij de informatie over de verschillende behandelingen evenwichtig gepresenteerd vonden. Geen enkele patiënt vond de informatie meer ten gunste van een stoma of meer ten gunste van een neoblaas gepresenteerd.

Met betrekking tot de keuze meldde een deel van de patiënten $(30 \%)$ dat de keuzehulp hen 'niet' had geholpen om een voorkeur te bepalen. Voor anderen hielp de keuzehulp 'een beetje' (45\%), 'veel' (20\%) of 'heel veel' (5\%). Alle patiënten $(100 \%)$ gaven aan dat zij de keuzehulp zouden aanraden aan anderen.

In de vragenlijst werd ook gevraagd naar eventuele problemen bij het gebruik van de keuzehulp. Op de vragen of er 'onbekende woorden' instonden of dat de inhoud 'te ingewikkeld' was, antwoordden alle patiënten dat dit zelden of nooit voorkwam.

\section{Wijze van inzetten door zorgverleners}

De meerderheid van de patiënten $(81 \%)$ gaf aan dat zij voldoende tijd kregen om de keuzehulp door te nemen en dat door de zorgverlener expliciet gevraagd werd naar hun voorkeur. Op de vraag of zij hun voorkeur met de arts konden bespreken gaf $10 \%$ aan dat zij geen voorkeur hadden, en van de overigen zei $78 \%$ 'ja, voldoende', $17 \%$ 'ja, maar onvoldoende', en $6 \%$ 'nee'. Van de mensen die nog vragen hadden, kreeg $86 \%$ deze voldoende beantwoord.

Het moment waarop de keuzehulp aan de patiënten werd aangeboden, varieerde: op de dag waarop de diagnose werd meegedeeld (38\%), de eerste week na de diagnose (19\%) of 
Hier staat een advertentie.

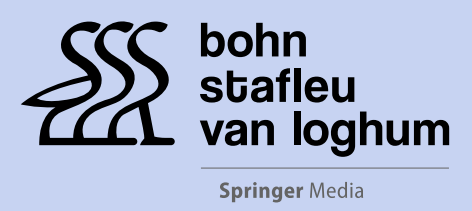

Houten 2019 
Hier staat een advertentie.

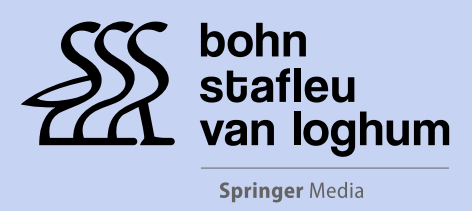

Houten 2019 

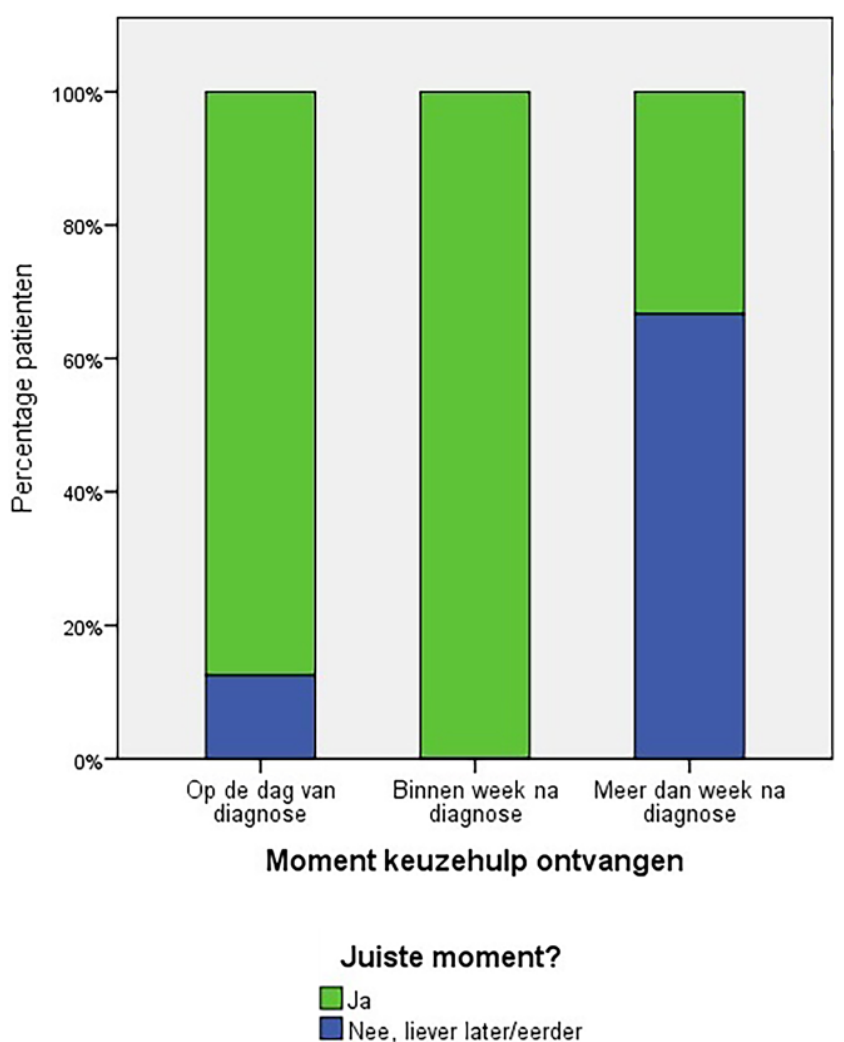

Figuur 2 Relatie tussen moment waarop keuzehulp werd aangeboden en het percentage patiënten dat dit het juiste moment vindt

langer daarna (43\%). De meeste deelnemers vond het moment waarop ze de keuzehulp ontvingen het juiste moment $(67 \%)$, terwijl een deel van hen deze liever eerder had ontvangen (24\%) en een deel liever later (10\%). In fig. 2 zijn de reacties uitgesplitst naar moment van ontvangen. Daarbij valt op dat de tevredenheid met de timing samenhangt met het moment waarop de keuzehulp werd ontvangen (respectievelijk $88 \%, 100 \%$ en $33 \% ; p=0,018)$.

\section{Discussie}

Uit een recente Cochrane review van 105 studies naar het effect van keuzehulpen is gebleken dat keuzehulpen in het algemeen zorgen voor actievere patiënten, meer kennis, meer samenhang tussen de behandelkeuze en de persoonlijke voorkeur en minder decisional conflict of twijfel over de keuze [24]. Ook deze keuzehulp zorgde voor meer actieve betrokkenheid van patiënten bij de keuze $(p=0,011)$. Daarnaast leidde de keuzehulp tot meer kennis en minder decisional conflict, maar de verschillen zijn in deze kleine pilotstudie niet statistisch significant. De toename in kennis is beperkt, mogelijk doordat het kennisniveau in de controlegroep al erg hoog is, waardoor sprake lijkt te zijn van een plafondeffect. De afname in decisional conflict van 4,8 is niet statistisch significant, maar is in orde van grootte wel vergelijkbaar met de significante afname van 6,0 die is gevonden in 18 studies in de Cochrane review [24]. Een beperking van de studie is dat er geen longitudinale data zijn verzameld over tevredenheid van patiënten op de langere termijn.

De manier waarop de keuzehulp in de praktijk is ingezet, is door patiënten positief beoordeeld. Patiënten kregen voldoende uitleg, hun vragen zijn beantwoord en ook is naar hun voorkeur gevraagd.

In deze studie hebben we tevens aandacht besteed aan het moment waarop de keuzehulp is aangeboden. Aanvankelijk bestond de zorg dat dergelijke informatie niet direct in het diagnosegesprek kan worden aangeboden, omdat eerst de diagnose zelf moet worden verwerkt. Deze veronderstelling blijkt onjuist. Aanbieden direct in het diagnosegesprek blijkt voor de meeste mensen niet te vroeg. Daarentegen lijkt aanbieden na meer dan een week voor de meeste patiënten later dan gewenst. Aanbieden tijdens of direct na het diagnosegesprek heeft bovendien logistieke voordelen.

Het is wenselijk dat de keuze van de urinederivatie een gezamenlijke beslissing is van patiënt en behandelend uroloog. In het geval dat de patiënt wordt verwezen voor operatie, kan de keuzehulp wel vast ter informatie worden uitgereikt. Patiënten die de keuzehulp pas later kregen aangeboden, gaven immers aan dat zij deze liever eerder hadden ontvangen. De uiteindelijke beslissing wordt echter genomen met de uroloog die de operatie zal uitvoeren.

De keuzehulp (www.stomaofneoblaas.nl) is goedgekeurd door de patiëntenvereniging Leven met blaas- of nierkanker en de beroepsverenigingen NVU en NV\&V en is vrij beschikbaar voor alle ziekenhuizen in Nederland die betrokken zijn bij de behandeling van blaaskanker.

\section{Conclusie}

Gebruikers beoordelen de keuzehulp voor een stoma of een neoblaas positief op inhoud en bruikbaarheid. Zij vinden de informatie over de voor- en nadelen van stoma en neoblaas die in de keuzehulp wordt aangeboden evenwichtig en niet te ingewikkeld. Gebruik van de keuzehulp leidt tot actieve deelname van de patiënten in de besluitvorming, waardoor hun voorkeur kan worden meegewogen bij de uiteindelijke keuze. Aanbieden van de keuzehulp kan direct na de diagnose.

Open Access This article is distributed under the terms of the Creative Commons Attribution 4.0 International License (http:// creativecommons.org/licenses/by/4.0/), which permits unrestricted use, distribution, and reproduction in any medium, provided you give appropriate credit to the original author(s) and the source, provide a link to the Creative Commons license, and indicate if changes were made. 


\section{Literatuur}

1. Bladder C, Hautmann RE, Abol-Enein H, et al. Urinary diversion. Urology. 2007;69:17-49. World Health Organization Consensus Conference.

2. Autorino R, Quarto G, Di Lorenzo G, et al. Health related quality of life after radical cystectomy: comparison of ileal conduit to continent orthotopic neobladder. Eur J Surg Oncol. 2009;35:858-64.

3. Evans B, Montie JE, Gilbert SM. Incontinent or continent urinary diversion: how to make the right choice. Curr Opin Urol. 2010;20:421-5.

4. Wright JL, Porter MP. Quality-of-life assessment in patients with bladder cancer. Nat Clin Pract Urol. 2007;4:147-54.

5. Cody JD, Nabi G, Dublin N, et al. Urinary diversion and bladder reconstruction/replacement using intestinal segments for intractable incontinence or following cystectomy. Cochrane Database Syst Rev. 2012;2:CD3306.

6. Bachir BG, Kassouf W. Urinary diversions: advantages and disadvantages of the major types of diversions. Curr Opin Support Palliat Care. 2013;7:249-53.

7. Ali AS, Hayes MC, Birch B, et al. Health related quality of life (HRQoL) after cystectomy: comparison between orthotopic neobladder and ileal conduit diversion. Eur J Surg Oncol. 2015;41:295-9.

8. Singh V, Yadav R, Sinha RJ, et al. Prospective comparison of quality-of-life outcomes between ileal conduit urinary diversion and orthotopic neobladder reconstruction after radical cystectomy: a statistical model. BJU Int. 2014;113:726-32.

9. Lee RK, Abol-Enein H, Artibani W, et al. Urinary diversion after radical cystectomy for bladder cancer: options, patient selection, and outcomes. BJU Int. 2014;113:11-23.

10. Philip J, Manikandan R, Venugopal S, et al. Orthotopic neobladder versus ileal conduit urinary diversion after cystectomy - a qualityof-life based comparison. Ann R Coll Surg Engl. 2009;91:565-9.

11. Chang DT, Lawrentschuk N. Orthotopic neobladder reconstruction. Urol Ann. 2015;7:1-7.

12. Monn MF, Kaimakliotis HZ, Cary KC, et al. Short-term morbidity and mortality of Indiana pouch, ileal conduit, and neobladder urinary diversion following radical cystectomy. Urol Oncol. 2014;32:1151-7.

13. Schrier BP, Laguna MP, Pal F van der, et al. Comparison of orthotopic sigmoid and ileal neobladders: continence and urodynamic parameters. Eur Urol. 2005;47:679-85.

14. Nieuwenhuijzen JA, Vries RR de, Bex A, et al. Urinary diversions after cystectomy: the association of clinical factors, complications and functional results of four different diversions. Eur Urol. 2008;53:834-42. Discussion 842-4.

15. Lee CT, Latini DM. Urinary diversion: evidence-based outcomes assessment and integration into patient decision-making. BJU Int. 2008;102:1326-33.
16. Kim SP, Shah ND, Weight CJ, et al. Population-based trends in urinary diversion among patients undergoing radical cystectomy for bladder cancer. BJU Int. 2013;112:478-84.

17. Sugihara $\mathrm{T}$, Yasunaga $\mathrm{H}$, Horiguchi $\mathrm{H}$, et al. Factors affecting choice between ureterostomy, ileal conduit and continent reservoir after radical cystectomy: Japanese series. Int J Clin Oncol. 2014;19:1098-104.

18. Parekh DJ, Donat SM. Urinary diversion: options, patient selection, and outcomes. Semin Oncol. 2007;34:98-109.

19. Witjes JA, Comperat E, Cowan NC, et al. EAU Guidelines on muscle-invasive and metastatic bladder cancer: summary of the 2013 Guidelines. Eur Urol. 2014;65:778-92.

20. Tol-Geerdink JJ van, Stalmeier PF, Lin EN van, et al. Do patients with localized prostate cancer treatment really want more aggressive treatment? J Clin Oncol. 2006;24:4581-6.

21. Tol-Geerdink JJ van, Leer JW, Lin EN van, et al. Offering a treatment choice in the irradiation of prostate cancer leads to better informed and more active patients, without harm to well-being. Int J Radiat Oncol Biol Phys. 2008;70:442-8.

22. Tol-Geerdink JJ van, Willem Leer J, Weijerman PC, et al. Choice between prostatectomy and radiotherapy when men are eligible for both: a randomized controlled trial of usual care vs decision aid. BJU Int. 2013;111:564-73.

23. Tol-Geerdink JJ van, Leer JW, Wijburg CJ, et al. Does a decision aid for prostate cancer affect different aspects of decisional regret, assessed with new regret scales? A randomized, controlled trial. Health Expect. 2016;19:459-70.

24. Stacey D, Legare F, Lewis K, et al. Decision aids for people facing health treatment or screening decisions. Cochrane Database Syst Rev. 2017;4:CD1431.

25. Elwyn G, O’Connor A, Stacey D, et al. Developing a quality criteria framework for patient decision aids: online international Delphi consensus process. BMJ. 2006;333:417.

26. Coulter A, Stilwell D, Kryworuchko J, et al. A systematic development process for patient decision aids. Bmc Med Inform Decis Mak. 2013;13(Suppl 2):2.

27. https://decisionaid.ohri.ca

28. O'Connor AM. Validation of a decisional conflict scale. Med Decis Making. 1995; 15:25-30.

dr. Julia J. van Tol-Geerdink onderzoeker medische besliskunde

dr. D.M. (Rik) Somford uroloog

dr. Carl J. Wijburg uroloog

dr. A.G. (Toine) van der Heijden uroloog

prof. dr. J.A. (Fred) Witjes uroloog 